\title{
Dietas para Leitões nas Fases de Creche e Diferentes Idades ao Desmame ${ }^{1}$ Messias Alves da Trindade Neto², Hacy Pinto Barbosa ${ }^{2}$, Izabel Marin Petelincar ${ }^{3}$, Eliana Aparecida Schammass ${ }^{4}$
}

\begin{abstract}
RESUMO - Oitenta leitões, metade desmamada aos 20 de idade e metade aos 25 dias de idade, com respectivos pesos: 4,55 $\pm 0,67$ e 6,62 $\pm 0,92 \mathrm{~kg}$, foram distribuídos em delineamento experimental de blocos casualizados em esquema fatorial, com cinco repetições e quatro animais por unidade experimental, visando-se estudar dois tipos de dieta e duas idades de desmame e seus efeitos nas fases de crescimento e terminação. As diferentes características das dietas foram obtidas com níveis de inclusão dos ingredientes: leite em pó desnatado, açúcar e óleo de soja. Não houve interação de dieta com idade ao desmame, e sim efeitos isolados dos fatores nas variáveis medidas. Até os 42 dias de idade, os leitões que consumiram a dieta com alta inclusão de leite em pó, açúcar e óleo tiveram melhor desempenho, enquanto o efeito da maior idade (25 dias) ao desmame influenciou apenas o ganho de peso. Dos 42 aos 63 dias de idade, a dieta com leite em pó propiciou melhor conversão alimentar e o efeito benéfico do desmame aos 25 dias de idade persistiu no ganho de peso. Os animais que consumiram dietas com altos níveis (40 e 20\%) do produto lácteo nos períodos de creche atingiram os $94,1 \mathrm{~kg}$ em menor tempo. Em relação aos que receberam as dietas com 10 e $0 \%$ de produto lácteo nas mesmas fases, a redução do período foi de 5 dias na idade final à terminação. Nas fases iniciais de crescimento, a alta inclusão de leite em pó desnatado favorece o desempenho dos leitões e a idade de desmame aos 25 dias é melhor do que a idade de desmame aos 20 dias. O acumulado das diferenças no desempenho, subseqüentemente aos tratamentos aplicados nos períodos de creche, deve ser melhor avaliado na idade final do suíno ao peso de abate.
\end{abstract}

Palavras-chave: crescimento, deposição lipídica, deposição protéica, leite em pó desnatado, terminação

\section{Diets for Piglets in the Nursery Phases and Different Ages at Weaning}

\begin{abstract}
Eighty piglets, half weaned at 20 days of age and half weaned at 25 daysof age, weighing $4.55 \pm 0.67$ and $6.62 \mathrm{~kg} \pm$ $0.92 \mathrm{~kg}$, respectively, were allotted to an experimental randomized block design in a factorial scheme, with five replicates of four animals per experimental unit, to evaluate two diets and two weaning periods and its effects in the growing and finishing phases. Different characteristics of diets were obtained with inclusion levels of ingredients: dried skin milk, sugar and soybean oil. There was no interaction between diets and weaning ages, but isolated effects of these factors on animal performance occurred. Piglets fed diet with high inclusion of dried skin milk and sugar and oil showed the best performance until 42 days, while the effect of the higher age was prominent only on weight gain. In the period from 42 to 63 days of age, the skin milk based diet allowed better feed/gain ratio and the effect of the oldest age persisted on weight gain. The animals fed diets with high levels of milk product (40 and 20\%) in nursery phases reached the $94.1 \mathrm{~kg}$ at minor age and compared to the ones that received 10 and $0 \%$ of milk products in same phases, the reduction time was of 5 days at finishing. In the beginning of the growing phase, the high level of dried skim milk favored the piglets performance and the weaning at 25 days. It is more recommended that weaning at 20 days. The accumulate of the differences subsequently to the nursery applied treatments must be better evaluated in the final age of pig at slaughter weight.
\end{abstract}

Key Words: dried skim milk, finishing, growing, lipidic deposition, protein deposition

\section{Introdução}

Com o rápido crescimento e acúmulo de massa muscular, tem sido alta a demanda nutricional do suíno nas fases iniciais do crescimento. Todavia, dietas à base de milho e farelo de soja oferecidas após o desmame, em substituição ao leite da porca (altamente digestível) predispõem o leitão a problemas fisiológicos digestivos, com implicações negativas no desempenho. Essas dietas não têm sido condizentes quantitativa e qualitativamente à produção enzimática pancreática e intestinal do leitão por ocasião do desmame antecipado (Kidder \& Manners, 1978).

$\mathrm{Na}$ tentativa de assegurar o desempenho satisfatório do leitão, minimizando os distúrbios digestivos do pós-desmame, vários autores têm estudado alternativas para melhorar as características das dietas fornecidas nos períodos afins, durante as fases

\footnotetext{
${ }^{1}$ Projeto financiado pela Fundação de Amparo à Pesquisa do Estado de São Paulo - FAPESP

2 Instituto de Zootecnia, Nova Odessa, SP, CP 60, CEP 13.460-000. E.mail: trindadeneto@izsp.br

${ }^{3}$ Engenheira-Agrônoma, Instituto de Zootecnia, Nova Odessa, SP, CP 60, CEP 13.460-000.

${ }^{4}$ Centro de Métodos Quantitativos, Instituto de Zootecnia, Nova Odessa, SP, CP 60, CEP 13.460-000. E.mail: schammass@izsp.br
} 
de creche (Mahan \& Newton, 1993; Mascarenhas et al., 1999; Trindade Neto et al., 1999).

Um dos aspectos enfatizados, dentre as características recomendáveis, para uma dieta destinada às fases iniciais do crescimento, tem sido a digestibilidade dos nutrientes presentes. Diversos estudos têm demonstrado que a digestibilidade das dietas empregadas no pós-desmame pode ser melhorada com a inclusão de produtos lácteos. Entretanto, os níveis dietéticos de produtos lácteos não devem ser inferiores a 25\% (Lepine et al., 1991). Em outros estudos são relatados que níveis superiores a $25 \%$ de produtos lácteos em dietas para leitões após o desmame, nas fases de creche, propiciam melhorias no desempenho (Mahan \& Newton, 1993; Trindade Neto et al., 1999) com reflexos positivos até a terminação (Tokach et al. 1995). Associada à melhoria do valor biológico da dieta, o aumento da inclusão dos produtos lácteos pode favorecer a concentração dos nutrientes e a expressão do potencial genético do animal, constatado pelo acúmulo de massa corporal.

Dietas com alta densidade energética são consideradas benéficas aos leitões nas fases de creche, porque a limitada ingestão de energia pode ser o fator de maior restrição à deposição protéica no suíno jovem (Batterhan, 1994). Além da quantidade, a fonte de energia pode ter efeitos no desempenho dos leitões. Porém a presença do óleo sobre as vilosidades pode prejudicar a digestão e a utilização dos nutrientes dietéticos nas primeiras semanas após o desmame antecipado já que, nesse período, a secreção da lipase pancreática ainda é limitada.

As dietas fornecidas nos períodos de creche podem ter efeito subseqüente no desempenho dos leitões, principalmente se estas contiverem grandes quantidades de produtos lácteos (Tokach et al., 1995; Trindade Neto et al., 1999).

Com base na inclusão de macroingredientes, foram avaliados os efeitos de dietas e idade ao desmame no desempenho de leitões, durante dois períodos de creche, e a ação residual dos tratamentos aplicados pósdesmame no desempenho, idade ao abate, taxas de deposição protéica e lipídica do corpo vazio.

\section{Material e Métodos}

O estudo foi realizado no Instituto de Zootecnia em Nova Odessa (fases de creche) e em Piracicaba (fases de crescimento e terminação) - SP.

Foram utilizados 80 leitões provenientes de cru- zamentos entre reprodutores e matrizes comerciais, machos castrados e fêmeas, desmamados aos 20 e 25 dias de idade, com respectivos pesos iniciais: 4,55 \pm 0,67 e $6,62 \pm 0,92 \mathrm{~kg}$. Foram distribuídos em delineamento experimental de blocos casualizados em esquema fatorial. $\mathrm{Na}$ formação dos blocos foram adotados os pesos iniciais para cada idade. Os tratamentos foram a combinação de duas dietas e duas idades ao desmame, em cinco repetições e quatro animais por unidade experimental.

As fases de creche consideradas foram: inicial-1 do desmame aos 42 dias; inicial-2 dos 42 ao 63 dias; e do desmame aos 63 dias de idade. O período experimental total foi de 43 e 38 dias para os leitões desmamados aos 20 e 25 dias de idade, respectivamente.

Na mudança de instalação, para acompanhamento subseqüente das fases de crescimento e terminação, a parcela original foi dividida em duas novas unidades experimentais. A nova parcela foi constituída por um macho castrado e uma fêmea.

A composição das dietas experimentais encontra-se na Tabela 1. Os valores de proteína bruta (PB) do milho, farelo de soja e leite em pó desnatado foram: 8,$52 ; 46,15$ e $33,58 \%$, respectivamente. Os demais dados utilizados na formulação das dietas foram obtidos em tabelas da EMBRAPA (1991) e NRC (1988). As diferenças das dietas ficaram caracterizadas pelos níveis de energia, proteína e aminoácidos, à exceção da lisina, obtidas com a inclusão de açúcar, óleo de soja e, principalmente, leite em pó. As relações estimadas de metionina + cistina, triptofano e treonina para a lisina, foram: 54,16 e $55 \%$ na dieta com $10 \%$ de leite em pó, 59,18 e $66 \%$ na dieta com $40 \%$ de leite em pó (fase inicial-1); 58, 18 e 58\% na dieta sem leite em pó, 64, 20 e $67 \%$ na dieta com $20 \%$ de leite em pó (fase inicial-2).

$\mathrm{Na}$ avaliação subseqüente, durante as fases de crescimento e terminação, os suínos receberam dietas à base de milho e farelo de soja, segundo as recomendações nutricionais do NRC (1988). Em todas as etapas de avaliação, alimentação e água foram fornecidas à vontade em comedouros semiautomáticos e bebedouros do tipo chupeta.

Um grupo de 16 leitões (4/tratamento) foi abatido ao final da fase de creche e terminação. Os dados médios obtidos ao término da etapa de creche serviram como valores comparativos na determinação das taxas de deposição protéica e lipídica à terminação. A taxa média de deposição foi obtida pela diferença entre a composição inicial e final, dividida pelo núme- 
Tabela 1 - Composição centesimal das dietas experimentais

Table 1 - Percentage composition of the experimental diets

\begin{tabular}{|c|c|c|c|c|}
\hline \multirow[b]{2}{*}{$\begin{array}{l}\text { Ingrediente \% } \\
\text { Ingredient }\end{array}$} & \multicolumn{2}{|c|}{$\begin{array}{l}\text { Inicial } 1: 20 \text { e } 25 \text { aos } 42 \text { dias idade } \\
\text { Initial-1: } 20 \text { and } 25 \text { at } 42 \text { days of age }\end{array}$} & \multicolumn{2}{|c|}{$\begin{array}{l}\text { Inicial } 1: 42 \text { aos } 63 \text { dias idade } \\
\text { Initial-1: } 42 \text { at } 63 \text { days of age }\end{array}$} \\
\hline & $\begin{array}{l}\text { Leite em pó } 10 \% \\
\text { Dried milk }-10 \%\end{array}$ & $\begin{array}{l}\text { Leite em pó } 40 \% \\
\text { Dried milk }-40 \%\end{array}$ & $\begin{array}{l}\text { Sem leite em pó } \\
\text { Whithout dried milk }\end{array}$ & $\begin{array}{l}\text { Leite em pó } 20 \% \\
\text { Dried milk- } 20 \%\end{array}$ \\
\hline $\begin{array}{l}\text { Milho comum }^{1} \\
\text { Common corn }^{1}\end{array}$ & 61,19 & 43,10 & 67,68 & 59,25 \\
\hline $\begin{array}{l}\text { Farelo de soja }{ }^{1} \\
\text { Soybean meal }\end{array}$ & 25,40 & 9,50 & 29,00 & 18,50 \\
\hline $\begin{array}{l}\text { Leite em pó desnatado } \\
\text { Skim dried milk }\end{array}$ & 10,00 & 40,00 & - & 20,00 \\
\hline $\begin{array}{l}\text { Açúcar refinado } \\
\text { Refined sugar }\end{array}$ & - & 4,00 & - & - \\
\hline $\begin{array}{l}\text { Óleo de soja } \\
\text { Soybean oil }\end{array}$ & - & 1,50 & - & - \\
\hline $\begin{array}{l}\text { Fosfato bicálcico } \\
\text { Dicalcium phosphate }\end{array}$ & 1,10 & 0,40 & 1,20 & 0,55 \\
\hline $\begin{array}{l}\text { Calcário calcítico } \\
\text { Limestone }\end{array}$ & 1,00 & 0,50 & 0,90 & 0,70 \\
\hline $\begin{array}{l}\text { Premix vitamina } \\
\text { Vitamin } \text { mix }^{2}\end{array}$ & 0,40 & 0,40 & 0,40 & 0,40 \\
\hline $\begin{array}{l}\text { Premix mineral } \\
\text { Mineral mix } \\
{ }^{3}\end{array}$ & 0,10 & 0,10 & 0,10 & 0,10 \\
\hline $\begin{array}{l}\mathrm{L} \text {-lisina } \mathrm{HCl} \\
\mathrm{L} \text { - lysine } \mathrm{HCl}\end{array}$ & 0,31 & - & 0,22 & - \\
\hline $\begin{array}{l}\text { Antibiótico } \\
\text { Antibiotic }\end{array}$ & 0,10 & 0,10 & 0,10 & 0,10 \\
\hline $\begin{array}{l}\text { Sal } \\
\text { Salt } \\
\text { Composição calculada } \\
\text { Calulated composition }\end{array}$ & 0,40 & 0,40 & 0,40 & 0,40 \\
\hline $\begin{array}{l}\text { Energia digestível }(\mathrm{kcal} / \mathrm{kg}) \\
\text { Metabolizable energy }\end{array}$ & 3425 & 3571 & 3417 & 3477 \\
\hline $\begin{array}{l}\text { Proteína bruta }(\%) \\
\text { Crude protein }\end{array}$ & 20,29 & 21,47 & 19,14 & 20,30 \\
\hline $\begin{array}{l}\text { Cálcio }(\%) \\
\text { Calcium }\end{array}$ & 0,86 & 0,83 & 0,74 & 0,73 \\
\hline $\begin{array}{l}\text { Fósforo total }(\%) \\
\text { Total P }\end{array}$ & 0,67 & 0,67 & 0,63 & 0,60 \\
\hline $\begin{array}{l}\text { Fósforo disponível (\%) } \\
\text { Available P }\end{array}$ & 0,42 & 0,53 & 0,35 & 0,39 \\
\hline $\begin{array}{l}\text { Lisina }(\%) \\
\text { Lysine }\end{array}$ & 1,40 & 1,40 & 1,20 & 1,20 \\
\hline $\begin{array}{l}\text { Metionina + cistina }(\%) \\
\text { Methionine }+ \text { cystine }\end{array}$ & 0,75 & 0,83 & 0,70 & 0,77 \\
\hline $\begin{array}{l}\text { Triptofano }(\%) \\
\text { Thryptofan }\end{array}$ & 0,23 & 0,26 & 0,21 & 0,24 \\
\hline $\begin{array}{l}\text { Treonina (\%) } \\
\text { Threonine }\end{array}$ & 0,77 & 0,93 & 0,69 & 0,81 \\
\hline
\end{tabular}

${ }^{1}$ Análises realizadas no Laboratório de Bromatologia do Instituto de Zootecnia (Analyses were performed at the Bromatologic Laboratory of Instituto de Zootecnia).

2 Conteúdo/kg (content/kg): A 2.250 .000 UI, vit. $D_{3} 450.000$ UI, vit. E 4.500 mg, vit. $K_{3} 400$ mg, vit. $B_{1} 350$ mg, vit. $B_{2} 1000$ mg, vit. $B_{6} 350$ mg, vit. $B_{12}$ $4500 \mathrm{mcg}$, Niacina (Niacin) 7500 mg, Ác. Pantotênico (Pantothenic acid) 4000 mg, Ác. Fólico (Pholic acid) 100 mg, Biotina (Biotin) 25 mg, Colina (Choline)

$75.000 \mathrm{mg}$, Promotor de Crescimento (Growth promoter) $19.000 \mathrm{mg}$, Antibiótico (Antibiotic) $16.500 \mathrm{mg}$ e Antioxidante (Anthioxidant) $25.000 \mathrm{mg}$.

${ }^{3}$ Conteúdo/kg (content/kg): Fe 80.000 mg, Cu 12.000 mg, Mn 70.000 mg, Zn 100.000 mg, I 1000 mg, Se 120 mg.

${ }^{4}$ Fosfato de tilosina (tylosin phosphate). 
ro de dias em teste. Adotando-se curtos intervalos de pesagens ao final da terminação, os animais correspondentes aos tratamentos oferecidos nas fases de creche foram amostrados ao atingirem o peso médio esperado, quando também foi aferida a idade média ao abate.

Os abates ocorreram após dezesseis horas de jejum, pelo método de sangria. O sangue foi coletado e pesado em sacos plásticos. Em seguida, as vísceras foram retiradas, esvaziadas e pesadas. Consideraram-se como vísceras: trato digestivo e urinário vazios e glândulas anexas, órgãos reprodutivos, coração, fígado, baço, pulmão, rins e gordura perirenal, conforme Quiniou \& Noblet (1995). A carcaça, que incluiu cabeça, pés, unhas e pêlos, foi serrada ao meio no sentido longitudinal e as metades pesadas individualmente. Em separado, vísceras e a metade direita da carcaça foram embaladas em sacos plásticos para prevenir a perda de umidade e, em seguida, mantidas a $10^{\circ} \mathrm{C}$ negativos até o processamento.

O processamento e preparo das amostras foram efetuados seguindo-se a metodologia descrita em Trindade Neto (1999).

As amostras de sangue, vísceras e carcaça foram submetidas ao processo de liofilização no Instituto de Tecnologia de Alimentos, Campinas - SP. O liofilizador utilizado foi o Stokes, sistema de vácuo a $3 \mathrm{mmHg}$ de pressão máxima em temperaturas inicial de menos $15^{\circ} \mathrm{C}$ e final de $10^{\circ} \mathrm{C}$, com secagem por sublimação.

Em cada fração corporal foram determinados os teores de matéria seca, proteína bruta, lipídeo e cinzas. A matéria seca considerada foi a liofilizada, contudo para correção do lipídeo, proteína bruta e matéria mineral, utilizou-se a obtida em estufa à temperatura de $105^{\circ} \mathrm{C}$, segundo Leme et al. (1994).

O corpo vazio foi definido como a diferença entre o peso vivo em jejum e os conteúdos estomacal, intestinal e da bexiga.

As análises estatísticas das variáveis experimentais foram realizadas através do pacote computacional SAS (1996) e as médias comparadas pelo teste F, conforme modelo:

$$
Y_{i j k}=m+D_{i}+I_{j}+B_{k}+(D I)_{i j}+e_{i j k} \text {, }
$$

em que: $\mathrm{Y}_{\mathrm{ijk}}=$ variável associada ao desempenho e taxas diárias de deposição; $\mathrm{m}=$ média geral da variável; $D_{i}=$ efeito da dieta $i$, sendo $i=1$ e 2 ; $\mathrm{I}_{\mathrm{j}}=$ efeito da idade de desmama $\mathrm{j}$, sendo $\mathrm{j}=1$ e 2 ; $\mathrm{B}_{\mathrm{k}}=$ efeito do bloco $\mathrm{k}$, sendo $\mathrm{k}=1,2, \ldots$ e 5 ; $(D I)_{i j}=$ efeito da interação dieta i e idade $j ; e_{i j k}=$ erro aleatório associado a cada observação.

\section{Resultados e Discussão}

Os resultados de desempenho dos leitões durante as fases inicial-1, inicial-2 e período total de creche encontram-se na Tabela 2. Em nenhuma das fases foi observada interação das características da dieta com a idade de desmama e sim efeitos principais dos dois fatores.

Do desmame aos 42 dias de idade, a dieta com $40 \%$ de leite em pó desnatado, $4 \%$ de açúcar e 1,5\% de óleo de soja proporcionou maior ganho de peso $(\mathrm{P}<0,01)$ e conversão alimentar $(\mathrm{P}<0,02)$ ao leitões, comparada àquela que continha $10 \%$ do produto lácteo. Considerando que a alta inclusão do leite em pó conferiu $41 \%$ do total da energia digestível e $60,5 \%$ da proteína bruta dietética, as características biológicas do ingrediente podem ter favorecido a distinção dos resultados nas variáveis do desempenho, conforme diferença $(\mathrm{P}<0,05)$ no peso vivo ao final do período. Segundo Cline (1991) a inclusão de produtos lácteos, em dietas contendo o farelo de soja, aumenta a digestibilidade, a utilização da energia e da proteína ou aminoácidos. Baseando-se nas informações do NRC (1998) todos os aminoácidos contidos no leite em pó desnatado possuem digestibilidade superior aos correspondentes do farelo de soja e milho.

Os resultados deste experimento ratificaram aqueles obtidos por Lepine et al. (1991) ao avaliarem, durante 21 dias de experimento, níveis dietéticos de lisina, na presença ou não de produtos lácteos, para leitões desmamados. Os autores constataram que a concentração do produto lácteo foi determinante nos resultados de desempenho, sugerindo, naquelas condições, nível mínimo de $25 \%$ para leitões recém desmamados. Em situação parecida, Mahan \& Newton (1993) recomendaram inclusão entre 35 e $45 \%$ dos produtos lácteos. Neste estudo, os distintos resultados de desempenho foram semelhantes aos encontrados por Tokach et al. (1995) nos primeiros 14 dias, quando determinaram os efeitos da adição de produtos lácteos (40\%) em dietas para leitões desmamados aos 23 dias de idade.

Em relação à idade, durante a fase inicial-1 os leitões desmamados aos 25 dias tiveram maior ganho de peso $(\mathrm{P}<0,07)$. Nas demais variáveis de desempenho não houve diferenças $(\mathrm{P}>0,05)$ embora os leitões desmamados aos 25 dias apresentassem cerca de $8 \%$ a mais no consumo de ração e na eficiência de utilização dos nutrientes dietéticos. Levando-se em 


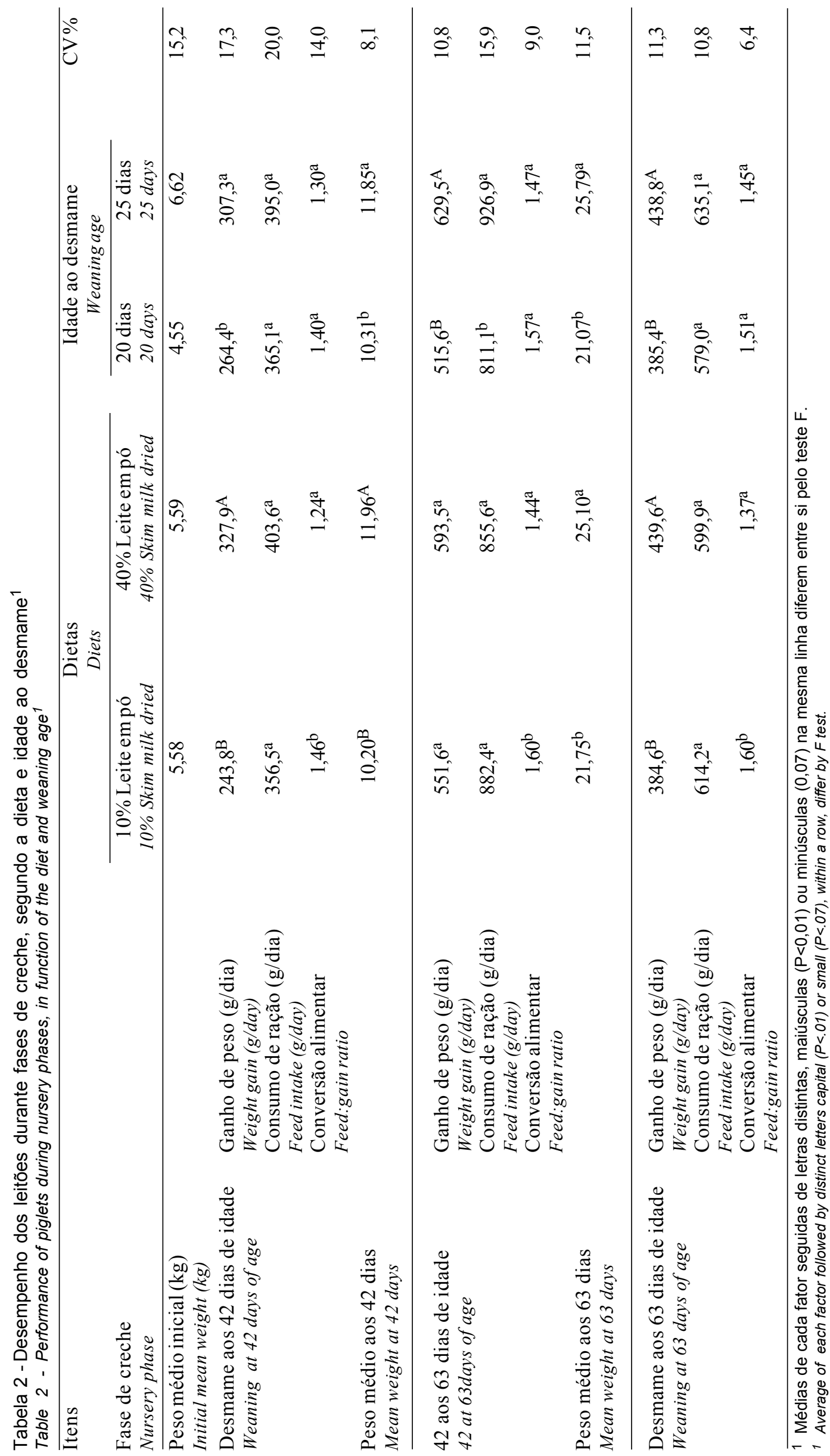


conta as condições fisiológicas digestivas do leitão, a diferença de idade pode ter favorecido os mais velhos, conforme observado ao final do período e em outros estudos anteriores. Implicações da idade no desenvolvimento do leitão foram feitas por Shields et al. (1980) observando que a atividade enzimática do pâncreas e da mucosa intestinal aumenta da segunda para décima semana de vida. Lima et al. (1990a,b,c) comparando três idades $(21,28$ e 35 dias) ao desmame, verificaram que os leitões mais velhos foram mais eficientes na utilização de proteína, lisina e energia.

Dos 42 aos 63 dias de idade (fase inicial-2) não foram observados efeitos $(\mathrm{P}>0,05)$ das dietas nas variáveis ganho de peso e consumo. Embora a diferença (Teste F) não seja significativa, os leitões que consumiram a dieta com $20 \%$ de leite em pó desnatado apresentaram $8 \%$ de ganho de peso superior aos que não consumiram o produto lácteo. $\mathrm{O}$ acumulado dessa variação diária sobre o ganho de peso evidenciou-se na diferença $(\mathrm{P}<0,05)$ ao final do período, quando os leitões que consumiram a dieta com produto lácteo atingiram maior peso vivo. Baseando-se na diferença de $3 \%$ entre consumos, a característica da dieta (com ou sem leite em pó) não foi o fator de interferência no desempenho; e sim a concentração do produto. Com o avanço da idade e do peso vivo dos leitões, o nível de inclusão de leite em pó pode ter propiciado a melhor conversão alimentar $(\mathrm{P}<0,03)$ caracterizando-se a maior eficiência de utilização dos nutrientes dietéticos. A melhor utilização dos nutrientes, provavelmente, decorreu do aumento da digestibilidade, visto que o produto lácteo conferiu $21 \%$ da energia e $31,4 \%$ da proteína bruta total na dieta.

Semelhante aos resultados para o ganho de peso e ingestão de alimento, durante a fase inicial-2 deste experimento, Trindade Neto et al. (1994) Berto et al. (1997) Carvalho (1998) e Mascarenhas et al. (1999) também não constataram diferenças significativas, quando compararam diversas dietas para leitões em período de creche.

O efeito da idade ao desmame na fase inicial-2 confirmou os resultados anteriores, observando-se que os leitões desmamados aos 25 dias apresentaram maior ganho de peso $(\mathrm{P}<0,01)$ e consumo de ração $(\mathrm{P}<0,07)$. Na conversão alimentar não houve influência $(\mathrm{P}>0,05)$ da idade de desmame. Em valores relativos, os leitões desmamados aos 25 dias consumiram mais $14,3 \%$ de alimento, apresentando melho- ra de 7\% na conversão alimentar. Além da provável e melhor condição fisiológica dos leitões desmamados aos 25 dias de idade, o maior consumo (energia, proteína e lisina) durante o período, possivelmente, favoreceu o desempenho. Os resultados ratificaram as observações de Lima et al. (1990a,b,c) sobre o desempenho dos leitões desmamados com maior idade, até atingirem $15 \mathrm{~kg}$ de peso vivo. Fazendo comparações a estudos anteriores, Mahan (1993) verificou que leitões mais velhos foram mais eficientes na utilização dos nutrientes, ao efetuarem o desmame aos 30 dias de idade.

No período total de creche, os leitões que consumiram a dieta com 40 (fase inicial-1) e $20 \%$ (fase inicial-2) de leite em pó desnatado apresentaram maior ganho de peso $(\mathrm{P}<0,01)$ e melhor conversão alimentar $(\mathrm{P}<0,05)$. Associado à pequena diferença na média de consumo entre as dietas experimentais, os percentuais de energia e proteína provenientes do produto lácteo, provavelmente, determinaram o maior desempenho do leitões. Reiterando os resultados verificados nas fases inicial-1 e 2, 41 e $21 \%$ da energia digestível, e 60,5 e $31,4 \%$ da proteína bruta originaram do leite em pó desnatado, conforme os cálculos das dietas. Os efeitos da inclusão do produto lácteo durante todo o período experimental confirmaram as observações de Lepine et al. (1991), Mahan $\&$ Newton (1993) e Tokach et al. (1995) em trabalhos semelhantes, avaliando o desempenho de leitões nas fases iniciais do crescimento.

Do desmame ao final do período de creche, os leitões desmamados aos 25 dias mostraram-se mais eficientes na utilização das dietas, apresentando maior ganho de peso $(\mathrm{P}<0,01)$ após consumirem quantidade de ração semelhante $(\mathrm{P}>0,05)$ aos desmamados com 20 dias de idade. Para as duas idades não foram observadas alterações na conversão alimentar $(\mathrm{P}>0,05)$. Na avaliação do período total de creche, os resultados confirmaram aqueles observados, separadamente, em cada fase, sugerindo-se que os leitões mais velhos teriam melhores condições fisiológicas digestivas por ocasião do desmame. Tais condições favoreceriam a distinção dos resultados em benefício dos desmamados aos 25 dias de idade. As implicações da idade no desenvolvimento do leitão foram abordadas por Shields et al. (1980), Lima et al. (1990a,b,c) e Mahan (1993).

Na determinação da composição química da carcaça e do corpo vazio, ao final das fases de creche, não houve diferenças estatísticas $(\mathrm{P}>0,05)$ entre os 
tratamentos. Os valores médios obtidos na carcaça foram: 66,60 água; 17,12 proteína; 13,24 lipídeo e 3,16\% matéria mineral. No corpo vazio foram: 69,70 água; 16,51 proteína; 11,16 lipídeo e 2,71\% matéria mineral.

Dados de desempenho, taxas diárias de deposição protéica e lipídica dos suínos, nas fases de crescimento e terminação são apresentados na Tabela 3 .

Ao final da fase de crescimento, não foram observados efeitos residuais dos tratamentos aplicados durante os períodos de creche no desempenho dos suínos. Apesar dos níveis de inclusão do produto lácteo nas dietas e a idade do desmame terem estabelecido as diferenças anteriores no desempenho, pôde-se observar que os efeitos dos tratamentos diluíram-se na fase de crescimento, quando os animais receberam uma dieta padrão. Os resultados confirmaram aqueles obtidos por Himmelberg et al. (1985), Berto et al. (1996) e Carvalho (1998), quando adotaram avaliação semelhante até a terminação.

Na terminação, os animais que haviam consumido dietas com alta inclusão do produto lácteo e foram desmamados aos 25 dias de idade apresentaram ligeira melhora na conversão alimentar $(\mathrm{P}<0,07)$. Nas demais variáveis de desempenho não houve diferenças significativas $(\mathrm{P}>0,05)$. $\mathrm{Na}$ ausência de diferença no ganho de peso, a pequena variação do consumo de ração pode ter influenciado a conversão ao final da terminação. A provável recuperação dos suínos ao final das fases de crescimento e terminação pode estar relacionada à limitação dos níveis nutricionais dietéticos, pois as dietas foram formuladas com base nas recomendações do NRC (1988). Considerando as atuais exigências nutricionais e a melhoria dos genótipos comerciais, o nível de lisina, bem como os demais aminoácidos, tornam-se fundamentais no processo de síntese protéica e ganho de peso.

As observações do estudo confirmaram os resultados obtidos por Berto et al. (1996) e Carvalho (1998) quando não constataram diferenças significativas no desempenho subseqüente aos tratamentos aplicados nas fases de creche. Não obstante, discordam daqueles verificados por Tokach et al. (1995) quando concluíram que o melhor desempenho propiciado pelas dietas suplementadas com níveis elevados de produtos lácteos, fornecidas nos períodos de creche, pode ser confirmado à terminação.

Neste estudo, constatou-se que no decorrer das fases de crescimento e terminação o acumulado das diferenças não significativas, sob o critério estatístico, no ganho de peso, não teve implicações $(\mathrm{P}>0,05)$ na idade final do suíno ao abate. Os animais que haviam consumido dietas com altos níveis (40 e 20\%) do produto lácteo nos períodos de creche atingiram os $94,1 \mathrm{~kg}$ em menor tempo. Em relação aos que receberam as dietas com 10 e $0 \%$ de produto lácteo nos mesmos períodos, a redução média da idade à terminação foi de 5 dias, entretanto pelo Teste F essa diferença não foi significativa. Tokach et al. (1995) inferiram sobre as implicações dietéticas do período de creche nos estágios subseqüentes até a terminação, sugerindo uma avaliação econômica que determine a viabilidade das dietas utilizadas anteriormente.

Baseando-se nas respostas dos tratamentos experimentais, aferidas na variável idade do suíno ao abate, a usual aplicação de alguns testes estatísticos na comparação de médias de desempenho deve ser melhor avaliada, sobretudo, ao considerar o fator produtividade.

Semelhante aos resultados de desempenho, no abate final não foram observadas diferenças $(\mathrm{P}>0,05)$ nas variáveis de composição corporal, deposição protéica e lipídica da carcaça e corpo vazio. Os valores médios das variáveis de composição química corporal foram: 55,74 água; 15,33 proteína; 26,66 lipídeo; e 2,93\% matéria mineral.

Das taxas diárias de deposição aferidas entre o término do período de creche e a terminação, a protéica ficou abaixo e a lipídica acima de grande parte dos resultados recentes obtidos na literatura estrangeira. Devido à baixa necessidade de nutrientes para a mantença durante as fases de maior crescimento do suíno (Close, 1994) pressupõe-se que a ingestão desses, nas fases subseqüentes ao período de creche, ficou abaixo da demanda metabólica para a potencial síntese e deposição protéica. Se ingeridos em quantidades desejáveis, a deposição lipídica torna-se mínima e o ganho muscular diferencia o peso nas fases de crescimento e terminação (Friesen et al., 1996).

A eficiência de utilização dos nutrientes e os reflexos nas taxas de deposição protéica também podem ser influenciados por fatores ambientais e situações experimentais. Williams et al. (1997) enfatizaram essa importância, ressaltando a pouca atenção dada ao assunto, nos estudos da Nutrição.

Pelas taxas de deposição protéica e lipídica obtidas à terminação, supõe-se que os níveis dietéticos dos nutrientes fornecidos nas fases de crescimento e terminação não atenderam as demandas para o ver- 


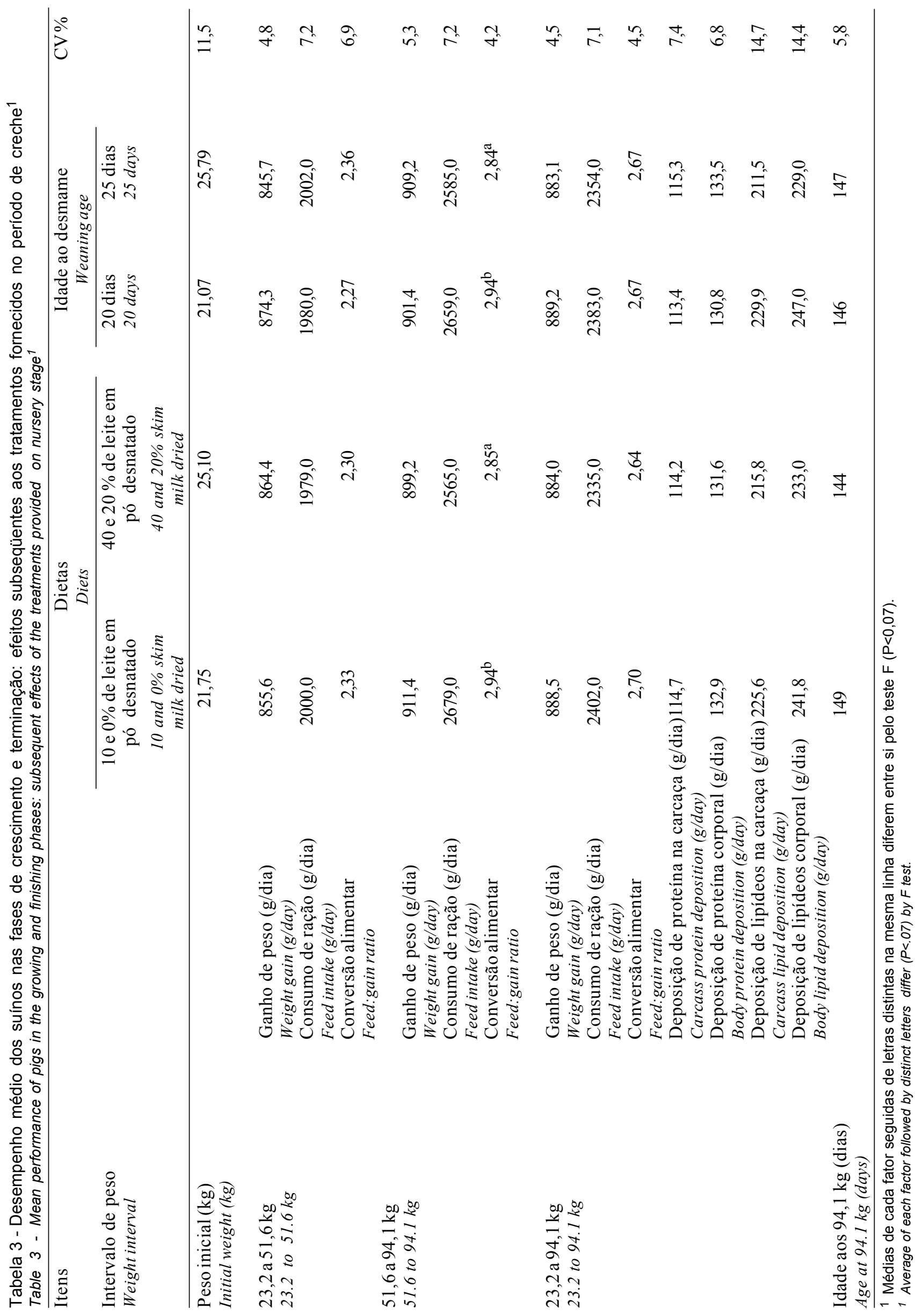


dadeiro potencial genético dos animais utilizados. Como a tabela do NRC (1988) compilou dados dos nove anos anteriores à publicação, os níveis nutricionais sugeridos encontravam-se defasados, por ocasião da realização do experimento, o que foi confirmado na sua nova edição (NRC, 1998).

\section{Conclusões}

Nos períodos iniciais do crescimento pós-lactente, a alta inclusão de leite em pó desnatado favorece o desempenho dos leitões e a idade de desmame aos 25 dias é melhor do que a idade de desmame aos 21 dias.

$\mathrm{O}$ acumulado das diferenças no desempenho, subseqüentemente aos tratamentos aplicados nos períodos de creche, deve ser melhor avaliado na idade final do suíno ao peso de abate, considerando, sobretudo, o fator produtividade.

\section{Literatura Citada}

BATTERHAM, E.S. Protein and energy relationships for growing pigs. In: COLE, D.J.A.; WISEMAN, J.; VARLEY, M.A. (Eds.) Principles of pig science. Nottinghan: Redwood Books, 1994. p.107-21.

BERTO, D.A.; KRONKA, R.N.; THOMAZ, M.C. et al. Efeito do período de fornecimento de ração semi-complexa na fase inicial, sobre o ganho de peso compensatório nas fases de crescimento e terminação. Revista da Sociedade Brasileira de Zootecnia, v.25, n.4, p.671-682, 1996.

BERTO, D.A.; KRONKA, R.N.; THOMAZ, M.C. et al. Efeito do tipo de dieta e sistema de alimentação na fase inicial sobre o desempenho de leitões. Revista Brasileira de Zootecnia, v.26, n.1, p.144-152, 1997.

CARVALHO, L.E. Desempenho de leitões recebendo na fase inicial diferentes níveis protéicos e tipos de dietas: Jaboticabal, Universidade Estadual Paulista, 1998. 82p. Tese (Doutorado em Zootecnia) - Universidade Estadual Paulista, 1998.

CLINE, T.R. Feeding pigs weaned at three to four weeks of age. In: MILLER, E.R.; ULLREY, D.E.; LEWIS, A.J. (Eds.) Swine nutrition, Butterworth-Heinemann, 1991. p.497-508.

CLOSE, W.H. Feeding new genotypes establishing amino acid/ energy requirements. In: COLE, D.J.A.; WISEMAN, J.; VARLEY, M.A. (Eds.) Principles of pig science. Nottinghan: Redwood Books, 1994. p.123-140, 1994.

EMPRESA BRASILEIRA DE PESQUISA AGROPECUÁRIAEMBRAPA. Tabela de composição química e valores energéticos de alimentos para suínos e aves. 3.ed. Concórdia: 1991, 97p.

FRIESEN, K.G.; NELSSEN, J.L.; GOODBAND, R.D. et al. The use of compositional growth curves for assessing the response to dietary lysine by high-lean growth gilts. Animal Science, v.62, n.1, p.159-169, 1996.

HIMMELBERG, L.V.; PEO Jr., E.R.; LEWIS, A.J. Weaning weight response of pigs to simple and complex diets. Journal of Animal Science, v.61, n.1, p.18-26, 1985.

KIDDER, D.E.; MANNERS, M.J. Digestion in the pig. England: Kingston Press, 1978. 201p.

LEME, P.R.; BOIN, C.; ALLEONI, G.F. et al. Estimativa da composição química corporal de novilhos nelore através do espaço deutério. Revista da Sociedade Brasileira de Zootecnia, v.23, n.3, p.441-452, 1994.
LEPINE, A.J.; MAHAN, D.C.; CHUNG, Y.K. Growth performance of weaning pigs fed corn-soybean meal diets with or without dried whey at various L-lysine-HCl levels. Journal of Animal Science, v.69, n.5, p.2026-2032, 1991.

LIMA, J.A.F.; PEREIRA, J.A.A.; COSTA, P.M.A. et al. Efeito da idade de desmama sobre as exigências de lisina para leitões na fase pré-inicial (desmama a 15kg PV). Revista da Sociedade Brasileira de Zootecnia, v.19, n.5, p.379-389, 1990a.

LIMA, J.A.F.; PEREIRA, J.A.A.; COSTA, P.M.A. et al. Efeito da idade de desmama sobre as exigências de proteína bruta para leitões na fase pré-inicial (desmama a $15 \mathrm{~kg}$ PV). Revista da Sociedade Brasileira de Zootecnia, v.19, n.5, p.362-369, 1990 b.

LIMA, J.A.F.; PEREIRA, J.A.A.; COSTA, P.M.A. et al. Efeito da idade de desmama sobre os níveis de energia digestível para leitões na fase pré-inicial (desmama a $15 \mathrm{~kg}$ PV). Revista da Sociedade Brasileira de Zootecnia, v.19, n.5, p.400-407, 1990c.

MAHAN, D.C. Evaluating two sources of dried whey component with corn gluten meal and lactose in the diets of weanling swine. Journal of Animal Science, v.71, n.11, p.2860-2866, 1993.

MAHAN, D.C., NEWTON, E.A. Evaluation of feed grains with dried skim milk and added carbohydrate sources on wealing pig performance. Journal of Animal Science, v.71, n.12, p.33763382, 1993.

MASCARENHAS, A.G.; FERREIRA, A.S.; DONZELE, J.L. et al. Avaliação de dietas fornecidas dos 14 aos 42 dias de idade sobre o desempenho e a composição de carcaça de leitões. Revista Brasileira de Zootecnia, v.28, n.6, p.1319-1326, 1999.

NATIONAL RESEARCH COUNCIL - NRC. Nutrients requirements of swine. 9.ed., Washington, D.C.: National Academy of Science, 1988. 93p.

NATIONAL RESEARCH COUNCIL - NRC. Nutrients requirements of swine. 10.ed., Washington, D.C.: National Academy of Science, 1998. 189p.

QUINIOU, N.; NOBLET, J. Prediction of tissular body composition from protein and lipid deposition in growing pigs. Journal of Animal Science, v.73, n.6, p.1567-1575, 1995.

SAS INSTITUTE - Statistical analysis systems user's guide. Version 6.12., Ed. Cary: 1996.

SHIELDS Jr., R.G.; EKSTROM, K.E.; MAHAN, D.C. Effect of weaning age and feeding method on digestive ensyme development in swine from birth to ten weeks. Journal of Animal Science, v.50, n.2, p.257-265, 1980.

TOKACH, M.D.; PETTIGREW, J.E.; JOHNSTON, L.J. et al. Effect of adding fat and (or) milk products to the weaning pig diet on performance in nursery and subsequent grow-finishing stages. Journal of Animal Science, v.73, n.11, p.3358-3368, 1995.

TRINDADE NETO, M.A.; LIMA, J.A.F.; BETERCHINI, A.G. et al. Dietas e níveis protéicos para leitões desmamados aos 28 dias de idade - fase inicial. Revista da Sociedade Brasileira de Zootecnia, v.23, n.1, p.92-99, 1994.

TRINDADE NETO, M.A.; BARBOSA, H.P.; DE SORDI, I.M.P. et al. Dietas contendo milho pré-gelatinizado e níveis protéicos para leitões desmamados aos 19 dias de idade. In: REUNIÃO ANUAL DA SOCIEDADE BRASILEIRA DE ZOOTECNIA, 36., 1999. Porto Alegre. Anais... Porto Alegre: Sociedade Brasileira de Zootecnia, 1999. CD ROM

TRINDADE NETO, M.A. Níveis de lisina para suínos nas fases iniciais de crescimento: efeitos no desempenho, no balanço de nitrogênio e na composição corporal: Jaboticabal: Universidade Estadual Paulista, 1999. 103p. Tese (Doutorado em Zootecnia) - Universidade Estadual Paulista, 1999.

WILLIAMS, N.H.; STAHLY, T.S.; ZIMMERMAN, D.R. Effect of chronic immune system activation on the rate, efficiency, and composition of growth and lysine needs of pigs fed from 6 to $27 \mathrm{~kg}$. Journal of Animal Science, v.75, n.9, p.2463-2471, 1997.

Recebido em: 18/04/01 Aceito em: 11/12/01 